\title{
Dissolution Rate Enhancement of Entacapone and Formulation of its Oro- Dispersible Tablets: Applying Statistical Design
}

\author{
Mahapatra Anjan Kumar ${ }^{1 \star}$, Padala Narasimha Murthy ${ }^{1}$, Nagampalli Haritha Sameeraja ${ }^{2}$ and Palei \\ Narahari Narayan ${ }^{3}$
}

${ }^{1}$ Royal College of Pharmacy and Health Sciences, Berhampur-2, INDIA. ${ }^{2}$ Central Drugs Standard Control Organization (Head Quarter), New Delhi, INDIA.

${ }^{3}$ Sree Vidyanikethan College of Pharmacy, Tirupati, INDIA.

\begin{abstract}
The major aim of the study was to enhance the solubility and dissolution rate of entacapone by complexation with cyclodextrins ( $\beta-C D / H P \beta-C D)$. Further the selected cyclodextrin complexes are deigned to formulate oro-dispersible tablets (ODTs) using selected concentration of PEG 4000 as hydrophilic polymer and crospovidone as superdisintegrant. The phase solubility behavior of entacapone in presence of various concentrations of $\beta-C D$, HP $\beta-C D$, PEG 4000, PVP and Poloxamer $188(0.25-5 \% \mathrm{w} / \mathrm{v})$ was studied at $37 \pm 2{ }^{\circ} \mathrm{C}$. Gibbs free energy $\left(\Delta \mathrm{G}^{\circ}{ }_{\mathrm{tr}}\right)$ values in negative, indicates the spontaneous nature of entacapone solubilization. From dissolution rate studies it was observed $\beta-C D$ complexes were better over HP $\beta-C D$ and are formulated to ODTs by direct compression method. Response surface modeling approach $\left(2^{3}\right.$ full factorial design) was used for design, development and data interpretation. The responses of the design were analyzed using Design Expert 8.0.7.1 (Stat-Ease Inc., USA). The optimized formulation was selected on the basis of software analysis with an overall desirability factor. The optimized formulation showed disintegration time of $40-42 \mathrm{~s}$, friability of $0.55 \%$ and a release of more than $85 \%$ within $45 \mathrm{~m}$. The physicochemical characterizations of inclusion complexes and the optimized tablet formulation were done by Fourier transform infrared spectroscopy (FTIR), scanning electron microscopy (SEM), differential scanning calorimetry (DSC), and X-ray diffraction (XRD).
\end{abstract}

Key words: Cyclodextrins, Entacapone, Inclusion complexation, Dissolution rate, Disintegration, $2^{3}$ Factorial design.

\section{INTRODUCTION}

The aqueous solubility and permeability of drug(s) through biological membranes are the main physicochemical properties that limit the bioavailability of a new drug molecule. Various methods are proposed to enhance aqueous solubility of poorly soluble drugs that includes: chemical modifications (e.g., pro drugs or salt derivatives), physical modifications (e.g., solid dispersions, size reduction, loading on porous carriers, co crystals), alteration of solvent compositions (e.g., $\mathrm{pH}$ adjustment, use of co solvents, addition of surfactants), and use of carrier systems (e.g., cyclodextrins, micelles, liposomes).

A simple and convenient solubilizing technique is the use of water-soluble cyclodextrins (CD) complexes. Among various approaches to improve solubility, inclusion complexation with cyclodextrins is a successful approach to improve dissolution rate and bioavailability of biopharmaceutical classification scheme (BCS) class II/ class IV drugs. Cyclodextrins are pharmaceutical solubilizing excipients that have the ability to temporarily camouflage undesirable
Submission Date : 23-02-2016 Revision Date : :04-04-2016 Accepted Date : :20-04-2016

DOI: 10.5530/ijper.50.4.7 Correspondence: Dr. Anjan Kumar Mahapatra Department of Pharmaceutics, Royal College of Pharmacy and Health Sciences, Berhampur-760 002, INDIA. Phone no: +91-9040160313 E-mail: dr.anjanmahapatra@ gmail.com

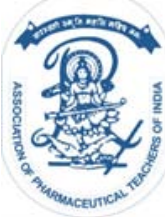

www.ijper.org 
physicochemical properties and offer desired therapeutic and drugable properties. Cyclodextrins can enhance oral dose availability, drug stability and affect permeability through biological membranes under certain circumstances. ${ }^{1}$ Cyclodextrins form a non-covalent dynamic inclusion complex in solution and help in solubilization of hydrophobic drugs. Cyclodextrins due to lipophilic interior and hydrophilic surface are capable of interacting with a number of guest molecules. Cyclodextrins and their derivatives have become popular excipients for increasing oral bioavailability of BCS class II and class IV drugs considering Fickian theory as well as the Noyes-Whiney relationship.,3

Entacapone, (E)-2-cyano3-(3, 4-dihydroxy-5-nitrophenyl)$\mathrm{N}, \mathrm{N}$-diethyl-2-propenamide is an add-on to levodopa to treat Parkinson's disease and is a potent, specific and orally acting peripheral catechol-O-methyltransferase (COMT) inhibitor (Figure 1). One $200 \mathrm{mg}$ tablet is taken with each levodopa/dopa decarboxylase inhibitor dose. The maximum recommended dose is $200 \mathrm{mg}$ ten times daily, i.e., $2000 \mathrm{mg}$ of entacapone. Entacapone decreases the metabolic loss of levodopa to 3-O-methyldopa (3-OMD) by inhibiting the COMT enzyme. It can be considered as a drug with low solubility and permeability, therefore entacapone belongs to BCS class IV. Entacapone appears as yellow non-hygroscopic crystalline powder, practically insoluble in water and especially in low $\mathrm{pH}$ and solubility is slightly higher above $\mathrm{pH} \mathrm{7,} \mathrm{soluble} \mathrm{or} \mathrm{sparingly} \mathrm{soluble} \mathrm{in} \mathrm{acetone,}$ slightly soluble in anhydrous ethanol, exhibits polymorphism as per the available literature. A drug is administered orally, must first dissolve in gastric fluids before permeating the gastrointestinal (GI) membrane to reach blood. Hence, poor aqueous soluble drug (s) (i.e., solubility $<1 \mathrm{mg} / \mathrm{ml}$ ) typically exhibit dissolution rate limited absorption, thus showing sub- optimal clinical efficacy and also few side effects. ${ }^{4-8}$

The dissolution study is important particularly for insoluble or low-soluble drugs, where absorption is a dissolution rate limited process for BCS class II and class IV drugs. Drugs those do not release completely in the GIT shows limited bioavailability which results in wastage of a large portion of an oral dose and adds cost of therapy. Improvement of solubility in such case is an important and challenging objective to improve therapeutic efficacy. ${ }^{9,10}$ Inclusion complexation of drugs with CDs may improve stability, solubility and dissolution. Here, effect of hydroxypropyl- $\beta$-cyclodextrins (HP $\beta$-CD) on aqueous solubility hence dissolution rate of entacapone was studied and was found increased. ${ }^{11,12}$
So far, the solid state (IR, DSC, XRD and SEM) and solution state (spectral analysis, phase solubility and dissolution rate) characterization of entacapone comparing $\beta-C D$ and $H P \beta-C D$ is not reported. Hand tremor due to Parkinson's disease and swallowing difficulties at old age can be managed by formulating an oro-dispersible tablet (ODT) of entacapone. A rationale with design and development of ODTs considering statistical tool has reported, which can be feasible for formulation and production at large or industrial scale.

\section{MATERIALS AND METHODS}

\section{Materials}

Entacapone was obtained as a gift sample from $\mathrm{M} / \mathrm{s}$ Aurobindo Pharmaceuticals (Hyderabad, India). The excipients such as $\beta$-CD and HP $\beta$-CD were received from Glenmark Pharmaceuticals, Mumbai, India. PEG 4000 and crospovidone was received from Colorcon Asia Pvt. Ltd., Verna, Goa, India. All other solvents and chemicals used in the study were of analytical grades.

\section{METHODS}

\section{Preparation of inclusion complexes}

Entacapone inclusion complexes of $\beta-C D$ and HP $\beta$-CD were prepared by kneading technique at ratios of 1:0.25, 1:0.5 and 1:0.75 w/w by using ethanol and water at $1: 1 \mathrm{v} / \mathrm{v}$ as solvent. The process parameters and operating levels are shown in Table 1. Obtained inclusions were dried at 45 to $50^{\circ} \mathrm{C}$. The dried solid inclusions were sieved through 60 mesh sieve and stored in desiccators.

\section{Phase solubility studies}

Solubility determination of entacapone was done in triplicate according to the method of Higuchi and Connors by adding an excess of entacapone to various concentrations of $\beta$-CD, HP $\beta$-CD, PEG 4000, PVP and Poloxamer-188 in water ranging from 0.25 to $5 \% \mathrm{w} / \mathrm{v}$ in screw capped glass vials. After $48 \mathrm{~h}$ of mixing in a water bath shaker (Remi Pvt Ltd, Mumbai), a definite volume was withdrawn and filtered through 0.45 micro meter polyvinylidene difluoride (PVDF) membrane (Sterlitech corporation, USA). Samples were analyzed by UV-analysis at $391 \mathrm{~nm}$ with suitable dilution, using Agilent Cary 60 UV-Visible spectrophotometer. The saturation solubility of drug in distilled water without taking hydrophilic carriers was also determined.

The Gibbs free energy values $\left(\Delta G_{t r}^{\circ}\right)$ for entacapone from water to different concentrations of carriers was 
determined from equation 1 , the values are given under Table 2.

$\Delta \mathrm{G}_{\mathrm{tr}}{ }^{0}=-2.303 \mathrm{RT} \log \left(\frac{\mathrm{So}}{\mathrm{Ss}}\right) \quad$ Equation 1.

Here, $\frac{\text { So }}{\mathrm{Ss}}$ is the ratio of molar solubility of drug in aqueous solution of carriers to that of the water. ${ }^{13-15}$

\section{IR Analysis}

The IR spectra were obtained by using an FT-IR spectrophotometer (Shimadzu Corporation, Japan). Scans were obtained at a resolution of $2 \mathrm{~cm}^{-1}$, from 4000 to $400 \mathrm{~cm}^{-1}$.

\section{SEM Study}

Surface characteristics of selected inclusions were evaluated from SEM study. The micrographs were recorded using scanning electron microscope (JEOL JSM-6100, Japan).

\section{Formulation of ODTs}

The selected drug- $\beta-C D$ inclusion complexes, PEG 4000, crospovidone and microcrystalline cellulose were passed through sieve no 60 , mixed properly and lubricated with sodium lauryl sulphate. The powder blend is compressed to tablets $(300 \mathrm{mg})$ using rotary tableting machine (Rimek mini press, Karnavati Engineering Ltd., India) employing $10 \mathrm{~mm}$ flat punches by direct compression. The batches were formulated using $2^{3}$ factorial design using three independent variables $\mathrm{X}_{1}, \mathrm{X}_{2}$ and $X_{3}$. Where $X_{1}$ is the ratio of $\beta-C D$ and drug, $X_{2}$ is the amount of PEG 4000 and $X_{3}$ is the amount of crospovidone. Two levels for each factor were selected $(-1,+1)$ indicating low, and high values. Eight formulations were prepared and evaluated for pre and postcompression parameters. The design layout and composition of $2^{3}$ factorial designs of entacapone ODT formulations are given in Table 3 and Table 4 respectively.

\section{Precompression parameters ${ }^{16,17}$}

Precompression parameters like angle of repose, bulk density, tapped density, Carr's consolidation index, and Hausner's ratio were evaluated for all formulation batches as per the official methods.

\section{Postcompression parameters}

\section{Content uniformity test}

For this test, twenty tablets were randomly selected, and assayed individually by UV-Visible spectrophotometer at $391 \mathrm{~nm}$. The required specification for this test is that uniformity of the dosage units should be within a range of $85-115 \%$.

\section{Hardness}

Hardness or crushing strength is the force required to break a tablet. This was measured using a tablet hardness tester (Electrolab, EH-01P).

\section{Friability test}

Twenty tablets were weighed and tested using Roche friabilator, operated at $25 \mathrm{rpm}$ for $4 \mathrm{~m}$. The percentage of weight loss was calculated after dedusting, using the formula:

$\%$ Friability $(f)=\left[\frac{\mathrm{W} 1-\mathrm{W} 2}{\mathrm{~W} 1}\right] \times 100 \quad$ Equation 2.

Where, $\mathrm{W}_{1}$ and $\mathrm{W}_{2}$ are the weight of tablets before and after test respectively.

\section{In vitro disintegration test}

For this test six tablets from each formulation were taken in $900 \mathrm{ml}$ of distilled water at $37 \pm 0.5^{\circ} \mathrm{C}$. The disintegration study was done in triplicate using USP disintegration test apparatus.

\section{In vitro dissolution studies}

The in vitro dissolution studies were conducted using $900 \mathrm{ml}$ of phosphate buffer ( $\mathrm{pH}$ 6.8) at $37 \pm 0.5^{\circ} \mathrm{C}$ at $50 \mathrm{rpm}$ using USP dissolution apparatus type II (Paddle type). Aliquots were collected at specified intervals of time i.e., $5,15,25,35$, and $45 \mathrm{~m}$, and analyzed at $391 \mathrm{~nm}$. Cummulative percent drug release was calculated. The study was done in triplicate $(n=3)$.

\section{Factorial design}

A statistical model incorporating interactive and polynomial terms was used to evaluate the responses:

$\mathrm{Y}=\mathrm{B}_{0}+\mathrm{B}_{1} \mathrm{X}_{1}+\mathrm{B}_{2} \mathrm{X}_{2}+\mathrm{B}_{12} \mathrm{X}_{1} \mathrm{X}_{2}+\mathrm{B}_{11} \mathrm{X}_{21}+\mathrm{B}_{22} \mathrm{X}_{22}$ Equation 3.

Where, $\mathrm{Y}$ is the dependent variable and $\mathrm{B}_{0}$ is the arithmetic mean response of the eight runs. $B_{1}, B_{2}, B_{12}, B_{11}$ and $B_{22}$ are estimates of the true values of the coefficients. The main effects $\left(\mathrm{X}_{1}\right.$ and $\left.\mathrm{X}_{2}\right)$ represent the average result of changing one factor at a time from its low to high value. The interaction term $\left(\mathrm{X}_{1} \mathrm{X}_{2}\right)$ shows how the response changes when two factors are simultaneously changed. The polynomial terms $\left(\mathrm{X}_{21}\right.$ and $\left.\mathrm{X}_{22}\right)$ are included to investigate nonlinearity. ${ }^{18}$

\section{Optimized formulation selection}

Design Expert software 8.0.7.1 was used to select the best formulation. Optimized formulation was selected on the basis of software analysis in addition to overall desirability value. Individual desirability for each response is confirmed by using reported methods. ${ }^{19}$ 
For a response to be minimized, the desirability function could be determined by using Equation 4 .

$$
\mathrm{d}_{1}=\left(\frac{\mathrm{Ymax}-\mathrm{Yi}}{\mathrm{Ymax}-\mathrm{Ymin}}\right) \quad \text { Equation } 4 .
$$

Where, $\mathrm{d}_{1}$ is the individual desirability of disintegration time, $Y_{i}$ represents the experimental result for each formulation, and $Y_{\min }$ and $Y_{\max }$ represent the lowest and the highest value found during the experiment, respectively. The desirability function for the response to be maximized, could be determined by equation 5 .

$$
\mathrm{d}_{2} \text { or } \mathrm{d}_{3}=\frac{\mathrm{Yi}-\mathrm{Ymin}}{\mathrm{Ymax}-\mathrm{Ymin}} \quad \text { Equation } 5 .
$$

Where, $d_{2}$ is the individual desirability of hardness, $d_{3}$ is the individual desirability of in vitro drug release.

The overall desirability value (D) could be determined using equation 6 .

$$
\mathrm{D}=\left(\mathrm{d}_{1} \mathrm{~d}_{2} \mathrm{~d}_{3}\right)^{1 / 3} \quad \text { Equation } 6 .
$$

\section{Differential scanning calorimetry (DSC)}

Measurements were performed using a DSC-4000 (Perkin Elmer, the Netherland) with a thermal analyzer. The process is operated at flow rate of nitrogen $20 \mathrm{ml} / \mathrm{m}$, at a scanning rate of $10^{\circ} \mathrm{C} / \mathrm{m}$ from 50 to $300^{\circ} \mathrm{C}$.

\section{$\mathrm{X}$-ray diffraction (XRD) analysis}

$X$-ray diffraction patterns of entacapone, $\beta$-CD, PEG 4000 , tablet formulation were analyzed using an X-ray diffractometer (X'Pert pro, PAN analytical, Netherland) with $\mathrm{Cu} \mathrm{K} \alpha$ radiation generated at $30 \mathrm{~mA}$ and $40 \mathrm{kV}$.

\section{Photo stability studies}

The photo stability study of methanolic solution of entacapone was conducted using the method as suggested by Ioele $e t$ al. The light degradation of entacapone was monitored by recording its absorption spectra in the wavelength range of $200-500 \mathrm{~nm}$ in a $10 \mathrm{~mm}$ quartz cell on a Shimadzu UV-Vis spectrophotometer at the following conditions: scan speed-slow; time response 1s; spectral band $1 \mathrm{~nm}$. $10 \mathrm{ml}$ of methanolic solution (concentration: $20 \mu \mathrm{g} / \mathrm{ml}$ ) was exposed to UV light. The samples were recorded just after preparation $(t=0)$ and at the time intervals of $5,30,60,90,120$ and $180 \mathrm{~m}$, after suitable dilution with methanol. ${ }^{20}$

\section{RESULTS AND DISCUSSION}

\section{Solubility studies}

Solubility experiments showed that the concentration of entacapone in water is notably affected by the presence of carriers. The aqueous solubility of entacapone was reported $80 \mu \mathrm{g} / \mathrm{ml}$ at $\mathrm{pH} \leq 5$ and the solubility increases with increased $\mathrm{pH} .{ }^{11}$ At $5 \% \mathrm{w} / \mathrm{v}$ concentration of $\beta$-CD and HP $\beta-C D$ under phase solubility study of entacapone, it was found significant increase. It has observed that hydrophilic carriers mainly interact with the drug molecules due to electrostatic bonds (i.e., ion-to-ion, ion-to-dipole, and dipole-to-dipole bonds), though other types of forces such as van der Waals forces and hydrogen bonds that can dominantly plays a vital role in the drug-carrier complexation. ${ }^{21}$ The Gibbs free energy values $\left(\Delta G_{t r}^{\circ}\right)$ associated with the solubility of entacapone in presence of carrier(s) in negative indicates the spontaneous nature of the drug solubilization, shown under Table 2.

\section{Fourier-transform infrared spectroscopy}

Entacapone shows a characteristic peak at $1604 \mathrm{~cm}^{-1}$ for carbonyl group stretching of amide functional group. Peaks at 3336, 2937, 2216 and $1541 \mathrm{~cm}^{-1}$ indicates presence of $\mathrm{O}-\mathrm{H}, \mathrm{C}-\mathrm{H}, \mathrm{C} \equiv \mathrm{N}$ and $\mathrm{NO}_{2}$ respectively. Peak at $1508 \mathrm{~cm}^{-1}$ confirms $\mathrm{C}-\mathrm{C}$ stretching. In the inclusion complexes with $\beta$-CD presence of characteristic peaks at 3223, 2937, 2216 and $1541 \mathrm{~cm}^{-1}$ may be due to O-H, $\mathrm{C}-\mathrm{H}, \mathrm{C} \equiv \mathrm{N}$ and $\mathrm{NO}_{2}$ stretch respectively. Peak at 1508 $\mathrm{cm}^{-1}$ confirms C-C stretching. Peak at $1734 \mathrm{~cm}^{-1}$ in the FT-IR spectrum indicates carbonyl group stretching of amide functional group. For the tablet formulation containing inclusion complex of drug - $\beta$-CD along with PEG 4000, the IR spectrum shows a characteristic peak at $1604 \mathrm{~cm}^{-1}$ for carbonyl stretching of amide group. Peaks at 3336, 2885 and $2216 \mathrm{~cm}^{-1}$ indicates presence of $\mathrm{O}-\mathrm{H}, \mathrm{C}-\mathrm{H}$ and $\mathrm{C} \equiv \mathrm{N}$ respectively. Peak at $1508 \mathrm{~cm}^{-1}$ confirms C-C stretching. The IR spectra are shown under Figure 2.

\section{Scanning electron microscopy (SEM)}

Scanning electron micrographs for drug and inclusion complexes with $\beta-C D$ at different magnifications are illustrated under Figure 3. Drug existed in crystalline particles. On the contrary, inclusion complexes appeared in the form of irregular particles in which the original morphology of both components disappeared and tiny aggregates of amorphous pieces of irregular size were present. Therefore the reduced particle size, increased surface area, and the close contact between the hydrophilic carriers and entacapone might be responsible for drug solubility in its complexes with $\beta$-CD.

\section{Precompression Parameters}

The precompression parameters such as bulk density, tapped density, angle of repose, Hausner's ration, and Carr's index of final active blends were studied and the 
results of the studies (F1-F8) are given under Table 3. The results of bulk density and tapped density were ranged from 0.253 to 0.367 and 0.316 to $0.452 \mathrm{~g} / \mathrm{cm}^{3}$, respectively. The results of angle of repose were ranged from 24.4 to 29.6 and indicated good flow properties which were further supported by Carr's index (15.02 to 21.06).

\section{Postcompression Parameters}

The results of postcompression studies are given in Table 4. All eight formulations were uniform in dimensions and exhibited content uniformity in the range from $99.13 \pm 0.87$ to $100.54 \pm 0.87$. The friability data of less than $1 \%$ were observed in all eight formulations and indicated sufficient resistance to abrasion. All the formulations passed weight variation test. The disintegration values less than $1 \mathrm{~m}$ were observed in all formulations. The crospovidone has a significant impact on disintegration. This may be due to swelling, and causing the tablet to a burst apart. The less disintegration time of tablets may be critical to further dissolution of the drug. However, the disintegration characteristics are not favored at higher the concentration of PEG 4000. Higher concentration of PEG 4000 retarded the disintegration which may be due to increase in cohesive effect between the particles as well as increase in viscosity and therefore drug release was also retarded.

\section{In vitro drug release studies}

The in vitro drug release of all eight formulations (F1-F8) is shown under Figure 4. The inclusion complexation and addition of crospovidone significantly enhanced the drug dissolution rate. The mechanisms for dissolution enhancement from inclusion complexes are many and not yet well understood. However, factors such as improved wettability, reduced aggregation and/ or agglomeration, increased effective surface area, loss of drug crystallinity, and solubilization effects associated with the carriers are assumed to be the main factors responsible for the results. ${ }^{22}$ Addition of PEG 4000 observed to improve dissolution rate of drug in tablets. As the concentration of PEG 4000 increased, entacapone dissolution rate was increased. The wetting effect of tablet was higher due to hydrophilic properties of PEG 4000 and it increased surface available for dissolution by reducing interfacial tension between the hydrophobic drug and the dissolution medium. ${ }^{23}$

The kinetic model fitting are analyzed for drug and formulations. Pure drug ranked first order model fitting, indicating the drug dissolution is concentration dependent and occurs by dissolution or erosion controlled with $\mathrm{n}$ value of 0.695 (K-P model) hence exhibits non
Fickian diffusion. The formulations ranked in the order of Hixson-Crowell cube root law > Korsemeyer-Peppas $>$ Higuchi (explains on drug release from polymer matrix) $>$ First order $>$ Zero order. Except for drug which exhibited first order and non Fickian diffusion, all the formulations showed Fickian diffusion..$^{24,25}$

\section{Factorial design}

\section{Hardness test}

The parameter hardness can be described by the following model equation:

Hardness $\left(\mathrm{Y}_{1}\right)=+3.01458+2.85000 \mathrm{X}_{1}+0.083750 \mathrm{X}_{2}-$ $0.012500 \mathrm{X}_{3}-0.24500 \mathrm{X}_{1} \mathrm{X}_{2}-0.1833 \mathrm{X}_{1} \mathrm{X}_{3}+0.018333 \mathrm{X}_{1} \mathrm{X}_{2} \mathrm{X}_{3}$ Equation 7.

The model $\mathrm{F}$ value of 177.62 indicates the model is significant $(\mathrm{P}<0.0001)$. A correlation plot between actual and predicted values of hardness is shown in Figure 5. The predicted R square of 0.9711 is in reasonable agreement with the adjusted $\mathrm{R}$ square of 0.99864 . In this case $\mathrm{X}_{1}, \mathrm{X}_{2}, \mathrm{X}_{1} \mathrm{X}_{2}, \mathrm{X}_{1} \mathrm{X}_{3}$ are significant model terms. Based on the polynomial equation positive sign of $\mathrm{X}_{1}$ and $\mathrm{X}_{2}$ showed agonistic effect on response. Out of two independent variables, $\mathrm{X}_{1}$ had higher value of co-efficient (2.85) compared to $\mathrm{X}_{2}(0.083)$ which indicated that $X_{1}$ had prominent effect on $Y_{1}$. Ratio of $\beta C D$ and drug had a prominent role on hardness of tablet. Surface porosity of tablet was decreased with increasing the ratio of $\beta-C D$ and drug could be a major role for improvement of the hardness of tablet. In presence of PEG 4000 the hardness effect of tablet was further increased. The polynomial equation showed that hardness was increased from $3.5 \pm 0.15$ to $3.9 \pm 0.21$ with increased concentration of PEG 4000. It may be due to the higher mechanical firmness and therefore lower porosity leading to increase in hardness of tablet. The response surface plot showed the effect of PEG 4000 and crospovidone on hardness of tablets is shown in Figure 6.

\section{In vitro disintegration time (DT)}

The parameter disintegration time can be described by the following model equation:

Disintegration time $\left(\mathrm{Y}_{2}\right)=+40.26389+51.0 \mathrm{X}_{1}+$ $0.42500 \mathrm{X}_{2}-0.75000 \mathrm{X}_{3}-1.30000 \mathrm{X}_{1} \mathrm{X}_{2}-3.66667 \mathrm{X}_{1} \mathrm{X}_{3}+$ $0.16667 \mathrm{X}_{1} \mathrm{X}_{2} \mathrm{X}_{3} \quad$ Equation 8.

The model $\mathrm{F}$ value of 43495.71 indicates the model is significant $(\mathrm{P}<0.0001)$. A correlation plot between actual and predicted values of DT is shown in Figure 5. The predicted R square of 1.000 is in reasonable agreement with the adjusted $\mathrm{R}$ square of 0.999 . In this case $\mathrm{X}_{1}, \mathrm{X}_{2}, \mathrm{X}_{3}, \mathrm{X}_{1} \mathrm{X}_{2}, \mathrm{X}_{1} \mathrm{X}_{3}, \mathrm{X}_{1} \mathrm{X}_{2} \mathrm{X}_{3}$ are significant model 


\section{Table 1: Process parameters and operating levels}

\begin{tabular}{|c|c|c|}
\hline Parameters & Low(-1) & High (+1) \\
\hline X1: $\beta-C D: D r u g$ & 0.25 & 0.75 \\
\hline X2: PEG 4000 $(\% \mathrm{w} / \mathrm{w})$ & 10 & 20 \\
\hline X3:crospovidone $(\% \mathrm{w} / \mathrm{w})$ & 9 & 15 \\
\hline
\end{tabular}

\begin{tabular}{|c|c|c|c|c|c|}
\hline \multirow{2}{*}{$\begin{array}{c}\text { CONCENTRATION OF } \\
\text { CARRIER IN WATER } \\
(\% \mathrm{~W} / \mathrm{V})\end{array}$} & \multicolumn{5}{|c|}{ GIBB'S FREE ENERGY $\Delta \mathrm{G}_{\mathrm{tr}}{ }^{0}(\mathrm{~J} / \mathrm{MOL})$} \\
\hline & $\beta-C D$ & $\mathrm{HP} \beta-C D$ & PEG 4000 & PVP & POLOXAMER- 188 \\
\hline 0.25 & -5183.6 & -4984.2 & -4966.7 & -4881.7 & -4717.2 \\
\hline 0.5 & -5275.4 & -5166.2 & -5140.5 & -4920.4 & -5103.7 \\
\hline 1 & -5663.1 & -5374.6 & -5311.8 & -5154.1 & -5241.2 \\
\hline 3 & -6722.9 & -5612.2 & -5637.7 & -5343.6 & -5424.6 \\
\hline 5 & -9528.1 & -9550.7 & -9554.1 & -9475.8 & -9579.6 \\
\hline
\end{tabular}

\begin{tabular}{|c|c|c|c|c|c|c|c|}
\multicolumn{7}{|c|}{ Table 3: $2^{3}$ Full-factorial design of tablets and precompres- } \\
sion evaluated response parameters \\
\hline FC & X1 & X2 & X3 & AR $\left(^{\circ}\right)$ & BD (g/cc) & TD (g/cc) & Cl (\%) \\
\hline F1 & -1 & -1 & -1 & 24.4 & 0.362 & 0.426 & 15.02 \\
\hline F2 & -1 & -1 & +1 & 27.3 & 0.327 & 0.402 & 18.65 \\
\hline F3 & -1 & +1 & -1 & 25.5 & 0.311 & 0.394 & 21.06 \\
\hline F4 & -1 & +1 & +1 & 29.2 & 0.253 & 0.316 & 19.93 \\
\hline F5 & +1 & -1 & -1 & 25.9 & 0.302 & 0.379 & 20.31 \\
\hline F6 & +1 & -1 & +1 & 27.6 & 0.317 & 0.391 & 18.92 \\
\hline F7 & +1 & +1 & -1 & 28.1 & 0.338 & 0.411 & 17.76 \\
\hline F8 & +1 & +1 & +1 & 29.6 & 0.367 & 0.452 & 18.80 \\
\hline
\end{tabular}

AR: Angle of repose; BD: Bulk density; TD: Tapped density; Cl: Carr's compressibility index.

Table 4: $2^{3}$ Full-factorial design of tablets and postcompression evaluated response parameters

\begin{tabular}{|c|c|c|c|c|c|c|c|c|c|}
\hline FC & $\mathrm{X} 1$ & $\mathrm{X} 2$ & X3 & $\begin{array}{l}\mathrm{CU} \\
\text { (\%) }\end{array}$ & $\begin{array}{c}\mathrm{HN}^{*} \\
\mathrm{Kg} / \mathrm{cm}^{2}\end{array}$ & $\begin{array}{l}\text { FB } \\
\text { (\%) }\end{array}$ & $\begin{array}{c}\mathrm{DT}^{*} \\
\text { (second) }\end{array}$ & $\begin{array}{l}\mathrm{DD}^{*} \\
\text { (\%) }\end{array}$ & D \\
\hline F1 & -1 & -1 & -1 & $99.13 \pm 0.87$ & $3.5 \pm 0.15$ & $0.67 \pm .035$ & $42 \pm 3.5$ & $63 \pm 2.7$ & 0.38 \\
\hline $\mathrm{F} 2$ & -1 & -1 & +1 & $99.65 \pm 0.56$ & $3.2 \pm 0.24$ & $0.59 \pm .045$ & $34 \pm 2.9$ & $69 \pm 2.4$ & 0.0 \\
\hline F3 & -1 & +1 & -1 & $99.81 \pm 1.09$ & $3.5 \pm 0.19$ & $0.52 \pm .023$ & $46 \pm 2.1$ & $75 \pm 2.1$ & 0.63 \\
\hline F4 & -1 & +1 & +1 & $99.32 \pm 0.30$ & $3.8 \pm 0.16$ & $0.47 \pm .017$ & $40 \pm 2.3$ & $85 \pm 3.4$ & 0.85 \\
\hline F5 & +1 & -1 & -1 & $100.54 \pm 0.87$ & $3.7 \pm 0.34$ & $0.61 \pm 0.045$ & $52 \pm 2.7$ & $57 \pm 2.8$ & 0.0 \\
\hline F6 & +1 & -1 & +1 & $99.98 \pm 0.76$ & $3.4 \pm 0.27$ & $0.62 \pm .034$ & $38 \pm 3.1$ & $61 \pm 2.9$ & 0.31 \\
\hline $\mathrm{F} 7$ & +1 & +1 & -1 & $99.37 \pm 0.57$ & $3.6 \pm 0.18$ & $0.54 \pm .032$ & $57 \pm 1.6$ & $62 \pm 2.4$ & 0.0 \\
\hline F8 & +1 & +1 & +1 & $99.78 \pm 0.98$ & $3.9 \pm 0.21$ & $0.50 \pm .024$ & $50 \pm 2.8$ & $71 \pm 2.7$ & 0.53 \\
\hline
\end{tabular}

CU: Content uniformity; HN: Hardness; FB: Friability; DT: disintegration time; DD: Drug dissolved; D: Overall desirability

* chosen for optimization, Data presented as mean \pm S.D $(n=3)$. 


\begin{tabular}{|c|c|c|c|}
\hline \multicolumn{3}{|c|}{ Table 5: Analysis of variance (ANOVA) of calculated model for responses } \\
\hline Results of ANOVA & Hardness (kg/cm ${ }^{2}$ ) & $\begin{array}{c}\text { Disintegration } \\
\text { time (min) }\end{array}$ & Drug dissolved (\%) \\
\hline Regression & 0.70 & 845.75 & 1157.75 \\
Sum of squares & 7 & 7 & 7 \\
DF & 0.100 & 120.82 & 165.39 \\
Mean squares & 177.62 & 43495.71 & 735.08 \\
F ratio & $<0.0001$ & $<0.0001$ & $<0.0001$ \\
P & 0.9864 & 0.9999 & 0.9967 \\
\hline Correlation coefficient(R) & 0.66 & 0.12 & 0.70 \\
\hline Coefficient of variance (CV \%) & 0.024 & 0.053 & 0.47 \\
\hline Standard Dev. & & & \\
\hline
\end{tabular}

terms. The DT of tablets was found in the range from $34 \pm 2.9$ to $57 \pm 1.6 \mathrm{sec}$. The polynomial equation indicated that DT was decreased with increasing in the concentration of crospovidone. This may function by drawing water into the tablet, swelling, and causing the tablet to burst apart. The less DT of tablets may be critical to subsequent dissolution of the drug. Basing on the polynomial equation $\mathrm{X}_{1}$ and $\mathrm{X}_{2}$ showed agonistic effect on response. Independent variable, $\mathrm{X}_{1}$ showed much pronounced effect on $\mathrm{Y}_{2}$. The DT of the tablets was further increased with increasing the concentration of PEG 4000. This result could be related to the plastic nature of the PEG 4000 which, during compression could plasticize, soften, and partially fill the pores within the tablets, thus making their wettability properties poor. PEG 4000 also showed binding properties, while using more concentrations in tablets probably led to slower disintegration rate. The DT of tablets was increased with increasing the concentration of crospovidone; it may be due to viscous networks. The response surface plot demonstrated the effect of amount of $\beta$-CD, PEG 4000 and crospovidone on DT is shown in Figure 6.

In vitro drug release: The parameter in vitro drug release can be described by the following model equation: $\%$ Drug dissolved $\left(\mathrm{Y}_{3}\right)=+45.37500+11.00000 \mathrm{X}_{1}+$ $1.02500 \mathrm{X}_{2}+0.58333 \mathrm{X}_{3}-1.70000 \mathrm{X}_{1} \mathrm{X}_{2}-1.00000 \mathrm{X}_{1} \mathrm{X}_{2}+$ $0.058333 \mathrm{X}_{2} \mathrm{X}_{3}+0.033333 \mathrm{X}_{1} \mathrm{X}_{2} \mathrm{X}_{3}$ Equation 9.

The model $\mathrm{F}$ value of 735.08 indicates the model is significant $(\mathrm{P}<0.0001)$. A correlation plot between actual and predicted values of in vitro drug release is shown in Figure 5. The predicted R square of 0.9972 is in reasonable agreement with the adjusted $\mathrm{R}$ square of 0.9967. In this case $\mathrm{X}_{1}, \mathrm{X}_{2}, \mathrm{X}_{3}, \mathrm{X}_{1} \mathrm{X}_{2}, \mathrm{X}_{1} \mathrm{X}_{3}, \mathrm{X}_{2} \mathrm{X}_{3}, \mathrm{X}_{1}$ $\mathrm{X}_{2} \mathrm{X}_{3}$ are significant model terms. Based on the polynomial equation $\mathrm{X}_{1}, \mathrm{X}_{2}$ and $\mathrm{X}_{3}$ showed agonistic effect on response $\mathrm{Y}_{3}$. The $\mathrm{X}_{1}$ with higher value of co-efficient (11.0 as against to 1.02 with $\mathrm{X}_{2}$ and 0.58 with $\mathrm{X}_{3}$ ) showed much pronounced effect onY ${ }_{3}$. The in vitro dissolution of tablets was found in the range from $57 \pm 2.9$ to $85 \pm 3.1 \%$. The polynomial equation indicated that drug release was increased with increasing concentration of PEG 4000 and crospovidone. The enhancement of entacapone dissolution in presence of PEG 4000 can be attributed to the solubilization effect of the carrier and improved wettability/dispersibility of the drug upon administration. In fact, increasing the PEG 4000 concentration in formulations only to an optimum amount resulted in better drug dissolution and further

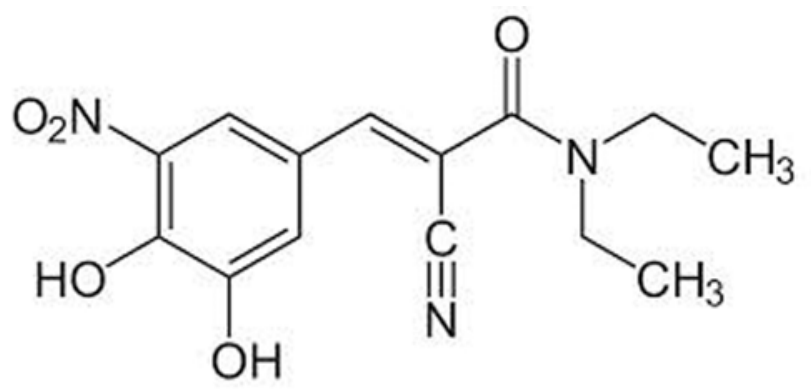

Figure 1: Structure of entacapone

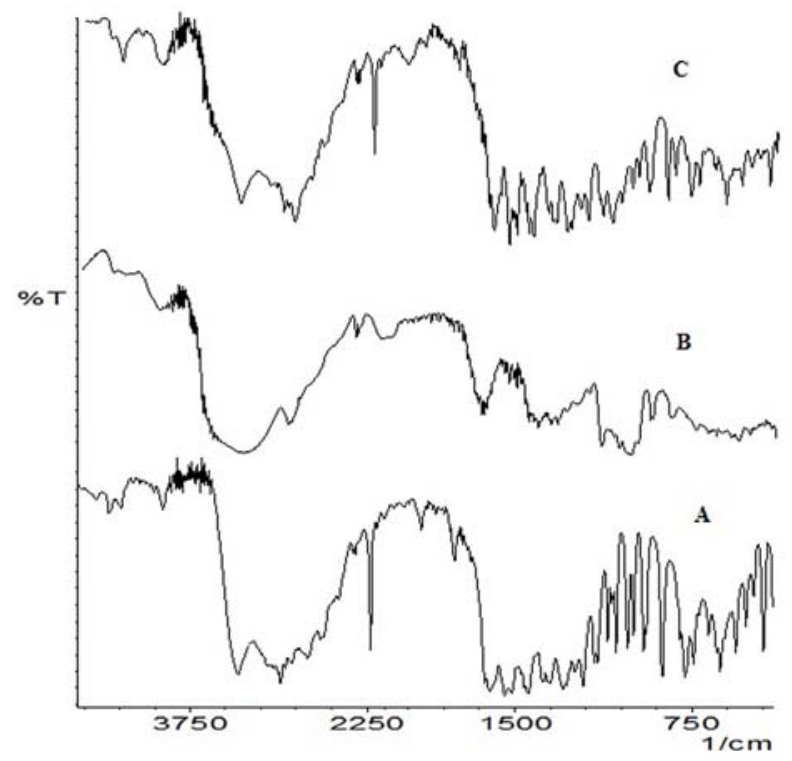

Figure 2: Fourier transform infrared spectroscopy of (A) Entacapone, (B) $\beta$ cyclodextrin, and (C) Entacapone $\beta$ cyclodextrin inclusion complex. 

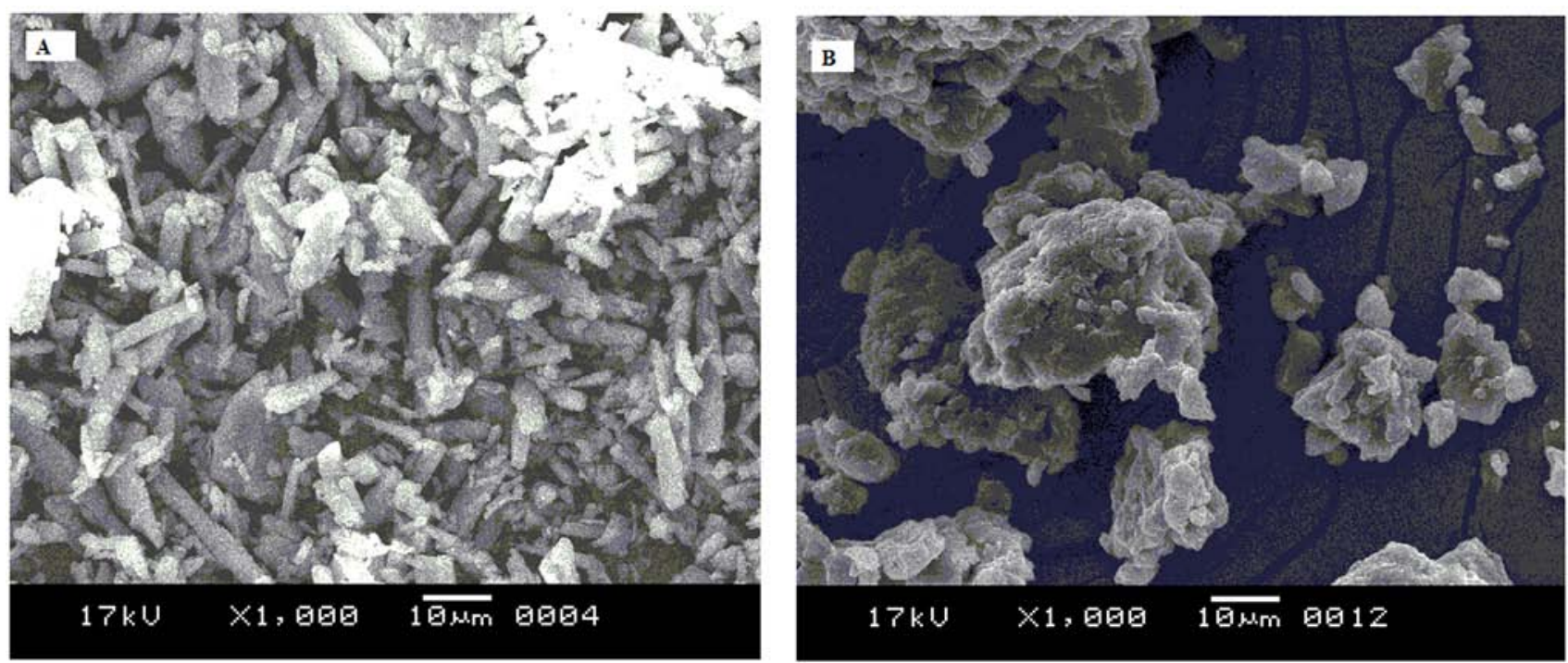

Figure 3: Scanning electron microscopy photograph of (A) Entacapone, and (B) Entacapone $\beta$ cyclodextrin inclusion complex.

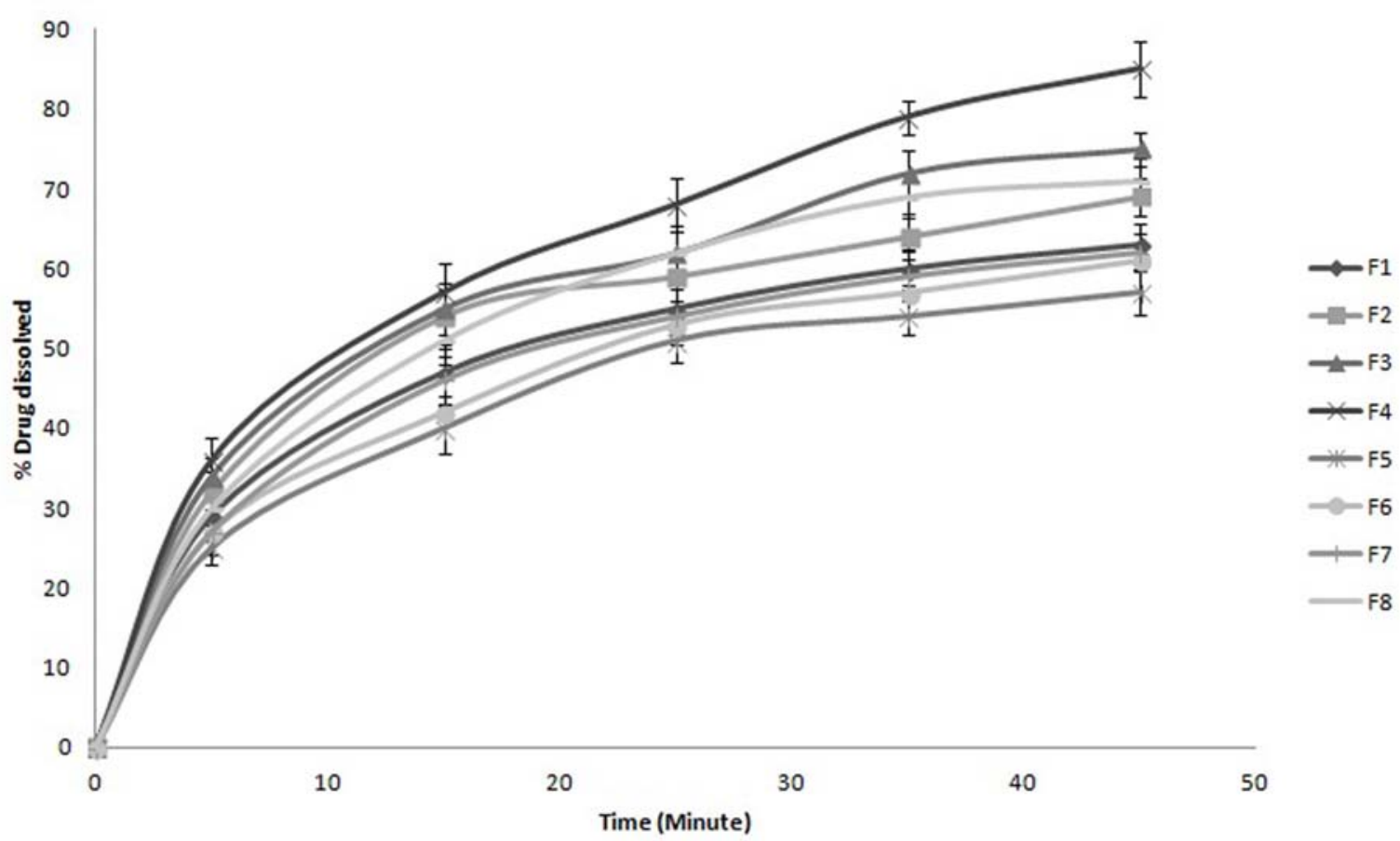

Figure 4: In vitro drug dissolution profiles of different formulations (F1-F8).

increase in polymer concentration, does not show any additional improvement. This might be attributed to the viscous layer formed around the solid particles due to higher PEG 4000 concentration and therefore decreased the diffusion coefficient (based on StokesEinstein equation) and lower drug dissolution. ${ }^{14}$ Addition of crospovidone leads to fast disintegration of tablets providing increased surface area and hence the disso- lution rate was found to be increased. ICs with $\beta$-CD increased the dissolution rate, due to the formation of water-soluble inclusion complexes. It clearly indicates the interactions between the hydrophobic part of the drug and the apolar cavity causes dehydration of the hydrophobic drug molecule and its transfer into the cavity, thereby increasing the affinity towards water and hence increasing the dissolution ${ }^{26}$. These findings 

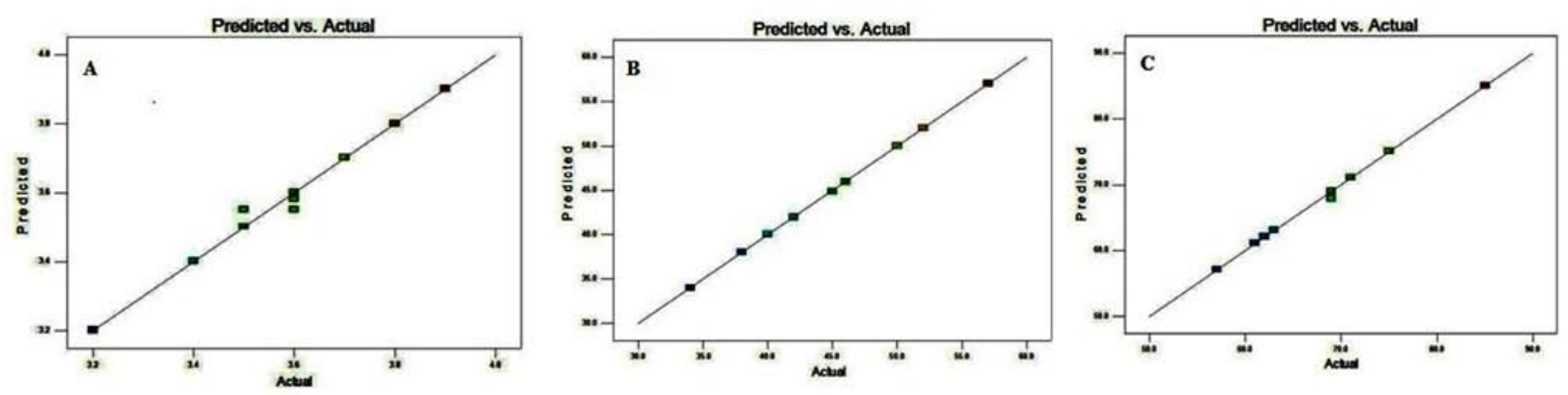

Figure 5: Linear correlation plot between actual versus predicted values for (A) Hardness $\left(\mathrm{kg} / \mathrm{cm}^{2}\right),(B)$ in vitro disintegration time (S), and (C) \% drug dissolved.

A

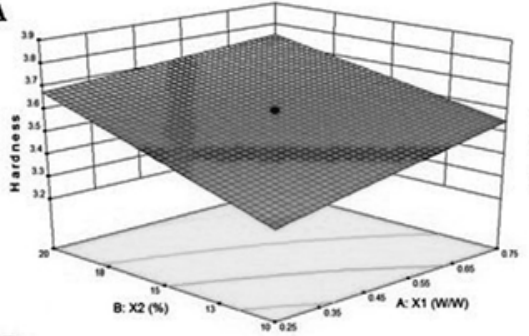

B

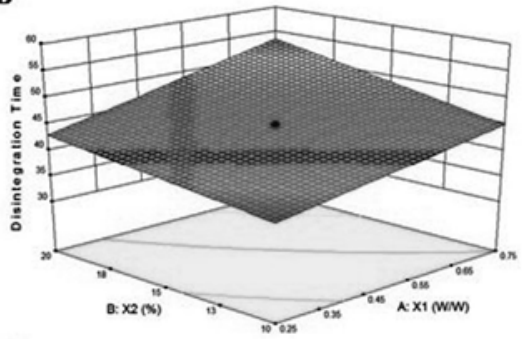

C

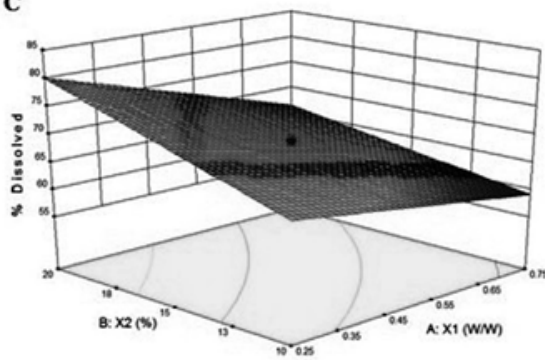

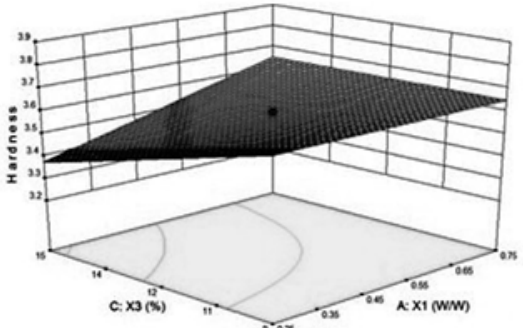
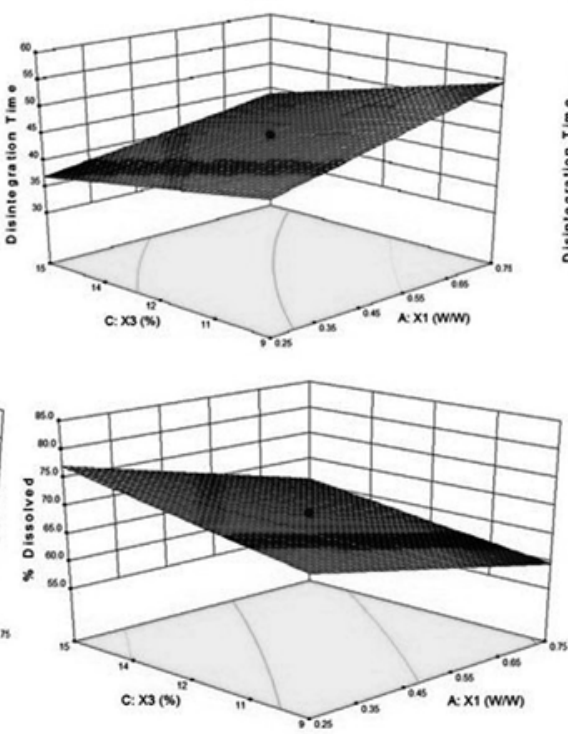
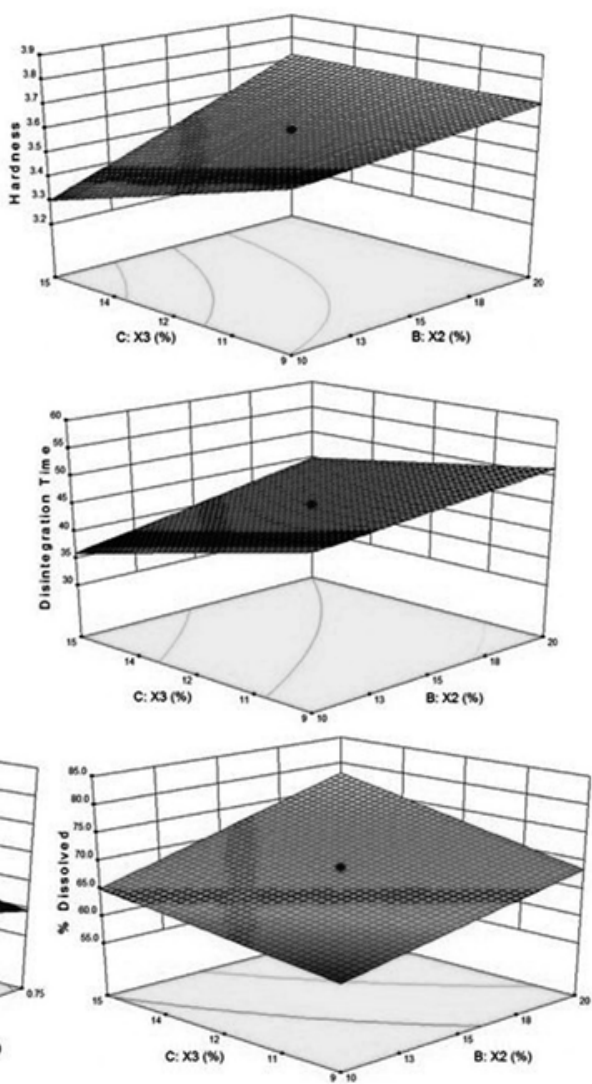

Figure 6: Response surface plot for (A) Hardness, (B) In vitro disintgration time , and (C) \% drug dissolved.

confirm that the addition of small amounts of PEG 4000 improves solubilizing and complexing ability of cyclodextrin which further related to increased release of drug in dissolution medium. Study signifies the use of PEG 4000 in combination with $\beta$-CD for the formation of inclusion complexes. ${ }^{27}$ Various response parameters and summary of regression analysis and ANOVA are shown in Table 5. Three dimensional response surface methodology (RSM) plots for hardness, disintegration time, and in vitro drug release are shown under Figure 6.

\section{Validation of response surface method (RSM) results}

Correlation plots between observed and predicted response variables shows linear relationship and is shown under Figure 5. The linear correlation plots drawn between the predicted and observed responses demonstrated high value of $\mathrm{R}^{2}$ for hardness (0.9920), disintegration time (1.000), and in vitro drug release 
Design-Expert@ Software Factor Coding: Actual

Desirability

- Design Points

$X 1=A: X 1$

$\mathrm{X} 2=\mathrm{B}: \mathrm{X} 2$

Actual Factor

C: $X 3=15$

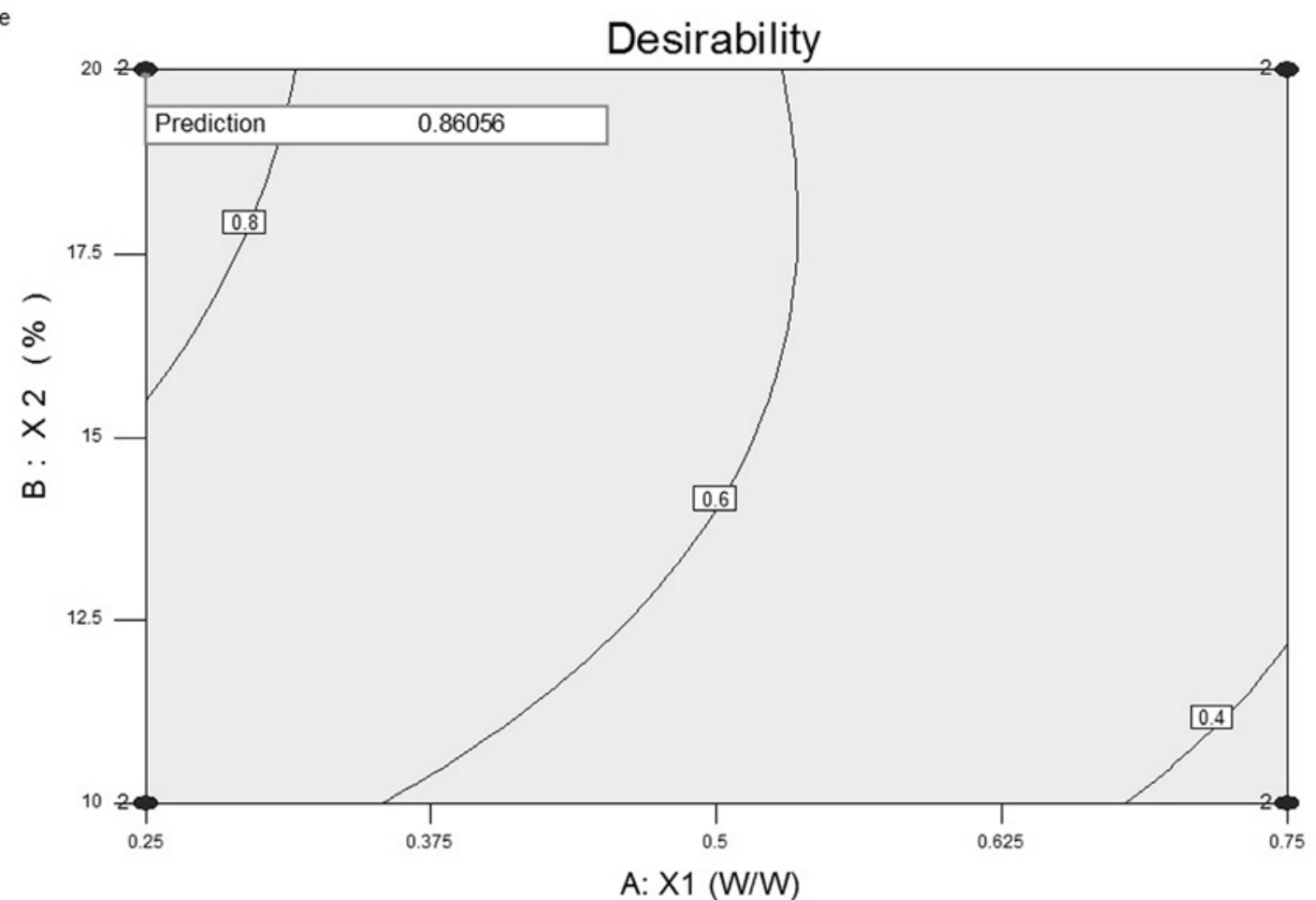

Figure 7: Desirability plot (2D).

Design-Expert@ Software Factor Coding: Actual Desirability

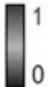

$\mathrm{X} 1=\mathrm{A}: \mathrm{X} 1$

$\mathrm{X} 2=\mathrm{B}: \mathrm{X} 2$

Actual Factor

C: $X 3=15$

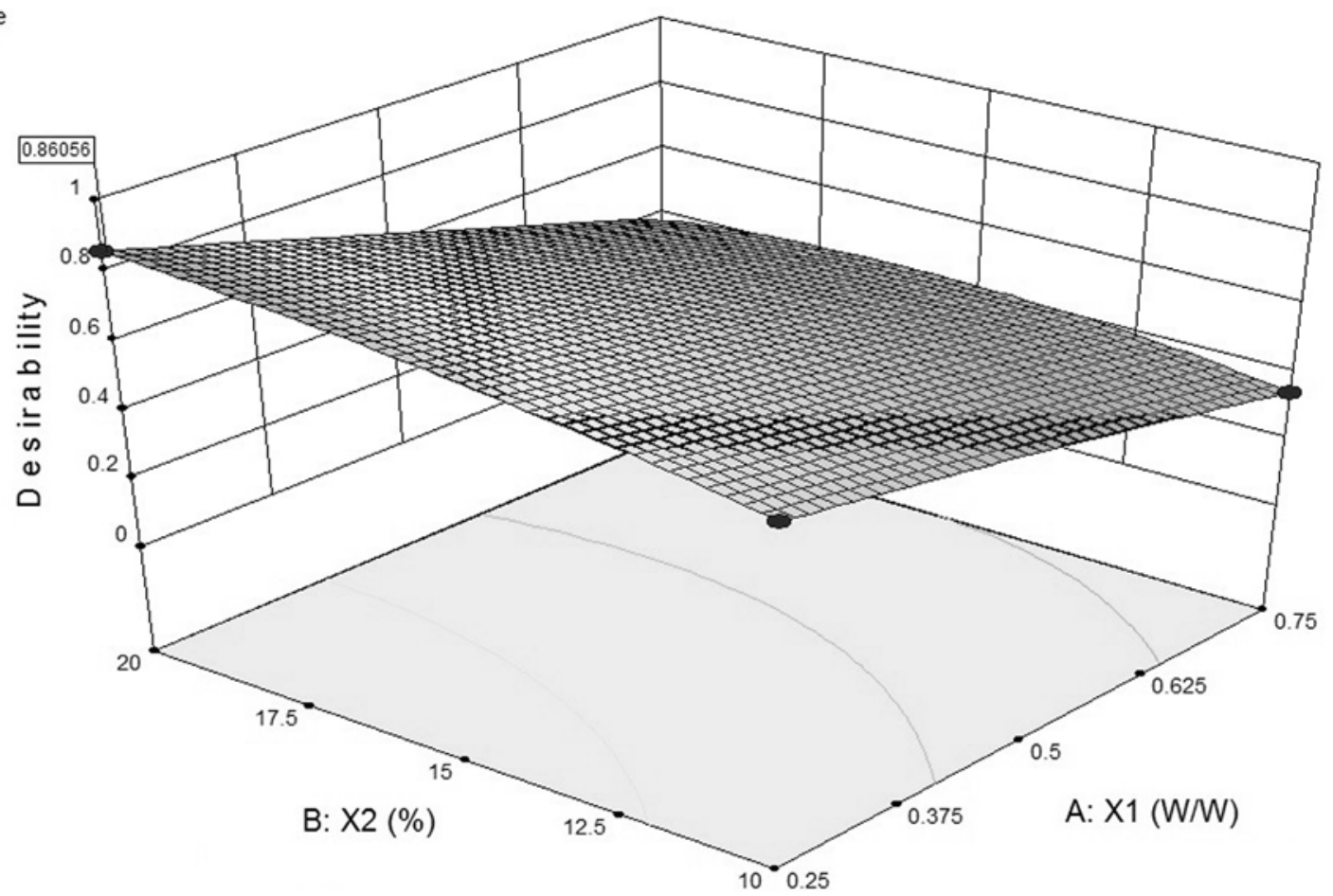

Figure 8: Desirability plot (3D). 


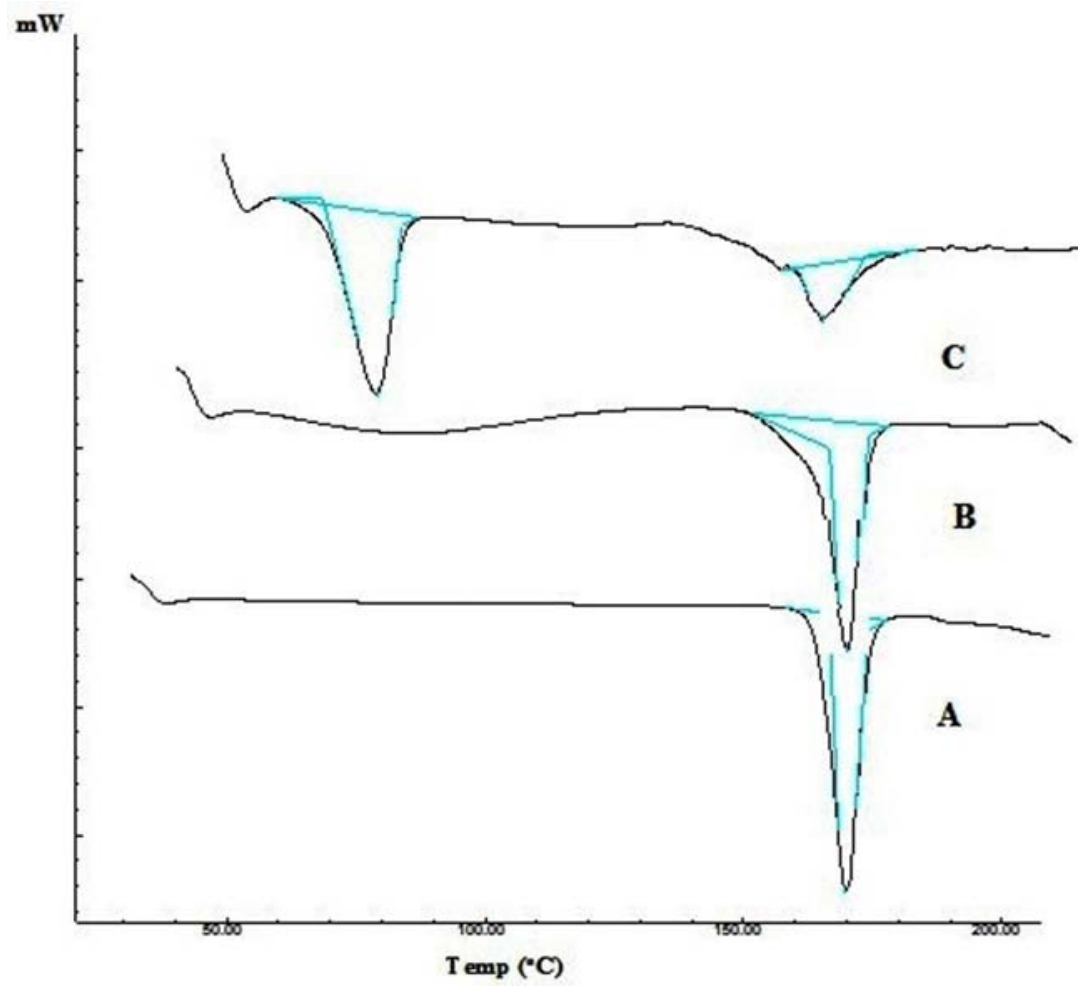

Figure 9: Differential scanning calorimetry curves of (A) Entacapone, (B) Entacapone $\beta$-cyclodextrin inclusion complex, (C) Optimized formulation (F4).

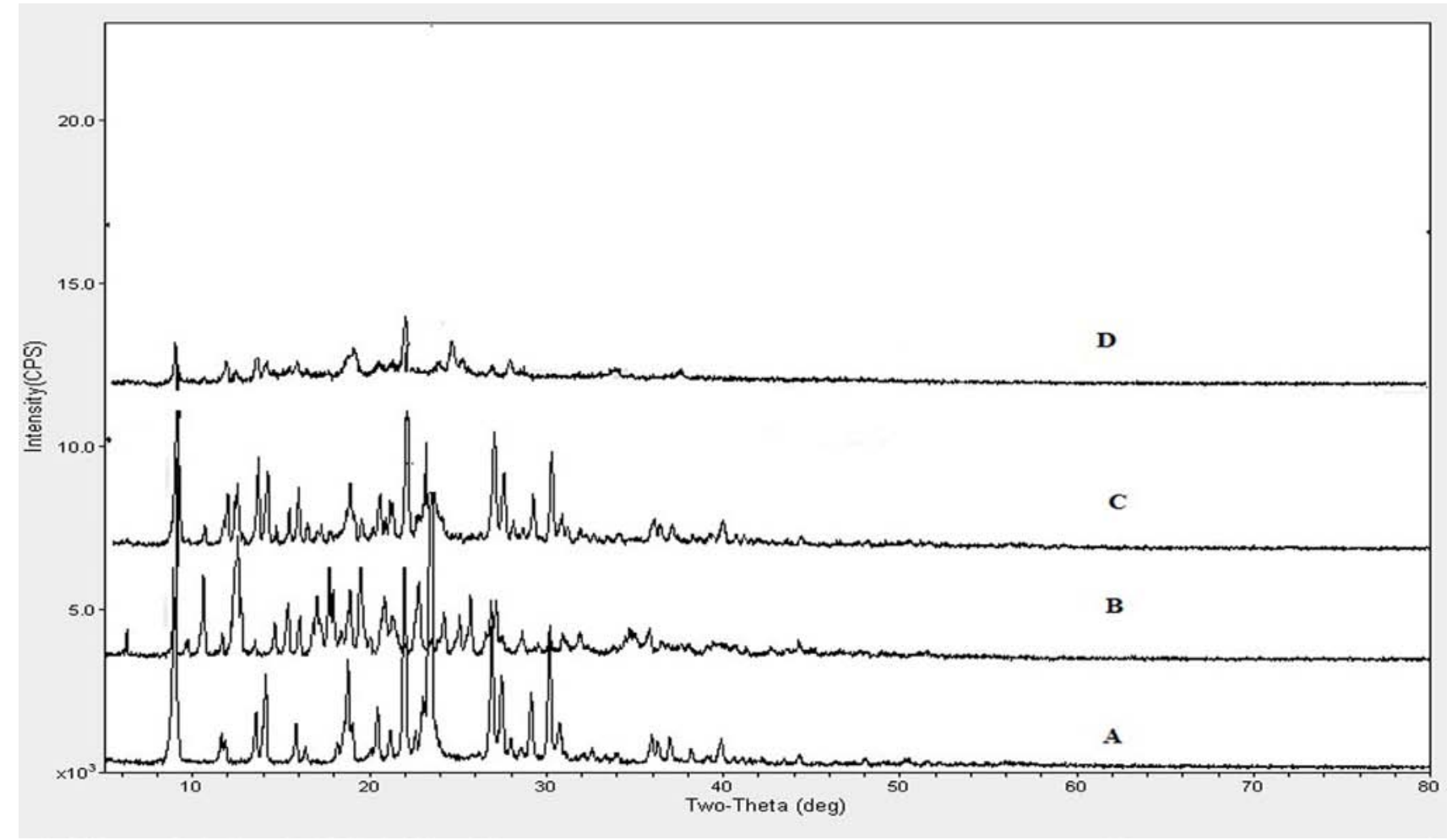

Figure 10: $X$ ray diffraction of (A) Entacapone, (B) $\beta$ cyclodextrin, (C) PEG 4000, and (D) Optimized formulation (F4). 
(0.9981) indicating excellent goodness of fit $(\mathrm{P}<0.001)$. All checkpoint formulation exhibited $>90 \%$ experimental validity. Thus, the low magnitude of error and the significant values of $\mathrm{R}^{2}$ in the current study indicated high prognostic ability of RSM.

\section{Formulation optimization using the desirability function:}

The principle of optimizing a pharmaceutical formulation is to find the levels of the variable that affect the chosen responses and determine the levels of the variable from which a robust product with high quality characteristics may be produced. The overall desirability function was calculated by using three responses and compared with the desirability plot. The formulation may be optimized based on an overall desirability function which was calculated using equations given under equations 4-6, and the results are shown in Table 4. Here the three responses such as hardness, disintegration time and $\%$ drug dissolved were used to optimize the formulation and fitted into the desirability scale $d_{1}$, $\mathrm{d}_{2}$ and $\mathrm{d}_{3}$ respectively. The results clearly indicate the formulation F4 with highest desirability value of 0.85 , which was considered the batch fulfilling all the constraints favorable for preparation of entacapone tablets. A numerical optimization technique using the desirability approach as shown in Figure 7 and Figure 8 was employed to develop a new formulation with the desired responses. Upon the evaluation, the formulation composition with $\beta-C D$ concentration and the amount of PEG 4000 which fulfilled maximum requirements of an optimum formulation with desirability of 0.8605 was observed. The desirability results revealed that there was no significant difference between calculated value and observed value.

\section{DSC study}

The DSC thermograms of the drug, drug- $\beta-C D$ inclusion complex and the formulation are shown in Figure 9. There was a complete disappearance of the characteristic endothermic peaks of entacapone and $\beta-C D$ in the thermogram. This is attributed to the formation of a true inclusion complex. However, there was a sharp endothermic peak at about $61^{\circ} \mathrm{C}$ due to the melting of PEG 4000. The presence of this peak was expected due to the high ratio of PEG 4000 in this formulation and it is not expected that $\beta-C D$ would form an inclusion complex with PEG 4000. The cavity of $\beta-\mathrm{CD}$ is too small to fit a large molecular weight substance such as PEG 4000. Considering these results, we can conclude the formation of an amorphous complex of entacapone and $\beta-C D$ dispersed in the PEG 4000 matrix. $^{28}$

$\mathrm{X}$-ray diffraction study: The XRD patterns of drug, $\beta-C D$, PEG 4000, and the formulation are shown in Figure 10. The diffraction patterns of $\operatorname{drug}, \beta-C D$, and PEG 4000 revealed several high intensity peaks, indicative of their crystalline nature. From XRD study it was confirmed that the intensity of peaks of entacapone tablet was lower as compared to pure drug, $\beta-\mathrm{CD}$ and PEG 4000. This indicates the formation of an amorphous complex of drug and $\beta$-CD dispersed in PEG 4000.

Photo stability studies: The spectral curves of the methanolic solution of entacapone $(20 \mu \mathrm{g} / \mathrm{ml})$ at the various times of UV exposure were recorded and there was no change on spectral curves at the end of $180 \mathrm{~m}$. It clearly indicates entacapone did not isomerize during the irradiation process.

\section{CONCLUSIONS}

The solubility and dissolution rate of entacapone can be enhanced by formulating its ICs with $\beta-C D$. Rapid dissolution of entacapone from the tablets formulated with PEG 4000 and crospovidone was seen. DesignExpert software was used to optimize and response surface plots and contour plots were drawn, and optimum formulations were selected by desirability function. Polynomial mathematical models generated for various response variables using multiple regression analysis were found to be statistically significant $(p<0.05)$. Formulation F4 was selected by the Design-Expert software which exhibited optimum hardness $(3.8 \pm 0.16$ $\left.\mathrm{kg} / \mathrm{cm}^{2}\right)$, disintegration time $(40 \pm 2.3 \mathrm{~s})$, and in vitro drug release $(85 \pm 3.1 \%)$ within $45 \mathrm{~m}$ is suitable for formulation development. With increased concentration of PEG 4000 up to optimum, entacapone dissolution rate was increased. The wetting effect of tablet was higher due to hydrophilic properties of PEG 4000 and it increased surface available for dissolution by reducing interfacial tension between the hydrophobic drug and the dissolution medium.

As per co-efficient of factorial design, $\beta$-CD had prominent effect on percentage drug release. Combination of $\beta-C D$ and PEG 4000 into entacapone tablet exhibited synergistic effect on the responses. Such an approach can be exploited for improving the dissolution rate of other low water soluble drugs. 


\section{ACKNOWLEDGEMENTS}

The authors are grateful to suppliers of drug and excipients as gift samples. Thanks to Maharajah's College of Pharmacy for providing necessary facilities to carry out the work and Ms. G. Anusha for her assistance.

\section{CONFLICTS OF INTEREST}

Herewith the author(s) declares that there is no conflict of interest regarding the publication of this article.

\section{REFERENCES}

1. Loftsson T and Brewster ME. Pharmaceutical applications of cyclodextrins: effects on drug permeation through biological membranes. J Pharm Pharmacol. 2011;63(9):1119-35.

2. Challa R, Ahuja A, Ali J, Khar RK. Cyclodextrins in drug delivery: an updated review. AAPS Pharm Sci Tech. 2005;6(2):329-57

3. Loftsson T, Brewster ME and Masson M. Role of Cyclodextrins in Improving Oral Drug Delivery. Am J Drug Deliv. 2004;2(4):1-15.

4. http://www.ema.europa.eu/docs/en_GB/document_library/EPAR_Public_ assessment_report/human/002075/WC500102610.pdf.

5. http://www.accessdata.fda.gov/drugsatfda_docs/nda/2003/21-485_ STALEVO_Chemr.pdf.

6. Holm KJ and Spencer CM. Entacapone a review of its use in Parkinson's disease. Drugs. 1999;58(1):159-77.

7. Ping G, Michael EG, Tiehua H, Juliane MB, Kevin JS and Qun L. Enhanced Oral Bioavailability of a Poorly Water Soluble Drug PNU-91325 by supersaturatable formulations. Drug Develop Ind Pharm. 2004;30(2):221-9.

8. Pallewar SK, Premchandani TA and Pethe AM. Unsuitability of pharmacopoeial dissolution conditions for entacapone: effects of various dissolution parameters on dissolution profile. J Pharm Neg Results. 2012;3(1):49-53.

9. Yu L X, Amidon GL, Polli JE, Zhao H and Mehta MU. The scientific basis for bio waiver extensions. Pharm Res. 2002;19(7):921-5.

10. Ozkan Y, Atay T, Dikmen N, Isimer A and Aboul-Enein HY. Improvement of water solubility and in vitro dissolution rate of gliclazide by complexation with beta-cyclodextrin. Pharm Acta Helv. 2000;74(4):365-70.

11. Savolainen J, Forsberg M, Taipale H, Mannisto PT, Jarvinen $\mathrm{K}$ and Jarvinen T. Effect of aqueous solubility and dissolution characteristics on oral bioavailability of entacapone. Drug Dev Res. 2000;49(4):238-44.

12. Nagarsenker MS and Joshi MS. Celecoxib-cyclodextrin systems: characterization and evaluation of in vitro and in vivo advantage. Drug Dev Ind Pharm. 2005;31(2):169-78.
13. Liu C, Desai $\mathrm{KGH}$, Liu C. Enhancement of dissolution rate of valdecoxib using solid dispersions with polyethylene glycol 4000. Drug Dev Ind Pharm. 2005;31(1):1-10.

14. Valizadeh $\mathrm{H}$, Nokhodchi A, Qarakhani N, Zakeri-Milani P, Azarmi S and Hassanzadeh D. Physico-chemical characterization of solid dispersions of indomethacin with PEG 6000, Myrij 52, Lactose, Sorbitol, dextrin, and Eudragit E100. Drug Dev Ind Pharm.2004;30:303-17.

15. Higuchi $\mathrm{T}$ and Connors K. Phase Solubility Techniques. Adv Anal Chem Instrum. 1965;4:17-123.

16. United States Pharmacopoeia 25/ National Formulary 20, The official Compendia of Standards. 2002:2010-3.

17. Indian Pharmacopeia, Government of India Minister of Health and Family Welfare, The Indian Pharmacopoeial Commission, Ghaziabad. 2014;2:959-61.

18. Harrington EC. The desirability function. Industr Qual Control. 1965;21:494-8.

19. Wei Z, Haoa J, Yuan S, Li Y, Juan W, Sha X and Fang X. Paclitaxel-loaded Pluronic P123/F127 mixed polymeric micelles: formulation, optimization and in vitro characterization. Int J Pharm. 2009;376(1):176-85.

20. Ioele G, Cione E, Risoli A, Genchi G and Ragno G. Accelerated photo stability study of tretinoin and isotretinoin in liposome formulations. Int $\mathrm{J}$ Pharm. 2005;293(1):251-60.

21. Cirri M, Mura P, Rabasco AM, Gine's JM, Moyano JR and GonzalezRodriguez ML. Characterization of ibuproxam binary and ternary dispersions with hydrophilic carriers. Drug Dev Ind Pharm. 2004;30:65-74.

22. Ruan LP, Yu BY, Fu GM and Zhu DN. Improving the solubility of ampelopsin by solid dispersions and inclusion complexes. J Pharmaceutics Biomed Analys. 2005;38(3):457-64.

23. Leonardi D, Barrera MG, Lamas MC and Salomón CJ. Development of prednisone: polyethylene glycol 6000 fast-release tablets from solid dispersions: solid state characterization, dissolution behavior, and formulation parameters. AAPS Pharm Sci Tech. 2007;8(4):E1-8.

24. Mahapatra AK, Murthy PN, Patra RK and Pattnaik S. Solubility Enhancement of modafinil by complexation with $\beta$-cyclodextrin and hydroxypropyl $\beta$-cyclodextrin: A response surface modelling approach. Drug Delivery Letters. 2013;3(3):210-9.

25. Mahapatra AK, Samoju S, Patra RK and Murthy PN. Dissolution enhancement of dronedarone hydrochloride by complexation with $\beta-C D$ and HP $\beta-C D$ : Dissolution and physicochemical characterization. Thai Journal of Pharmaceutical Sciences. 2014;38(3):139-48.

26. Dua K, Pabreja K, Ramana MV and Lather V. Dissolution behavior of $\beta$-cyclodextrin molecular inclusion complexes of aceclofenac. J Pharm Bioallied Sci. 2011;3(3):417-25.

27. Ansari M. Investigations of polyethylene glycol mediated ternary molecular inclusion complexes of silymarin with beta cyclodextrins. J Appl Pharmaceuti Sci. 2015;5(9):26-31.

28. Dollo G, Le Corre P, Chollet M, Chevanne F, Bertault M, Burgot JL and Le Verge R. Improvement in solubility and dissolution rate of 1, 2-ditiole-3thiones upon complexation with $\beta$-cyclodextrin and its hydroxypropyl and sulfobutyl ether derivatives. J Pharm Sci. 1999;88(9):889-95.

\section{SUMMARY}

- The solubility and dissolution rate of entacapone can be enhanced by formulating its ICs with $\beta-C D / H P$ $\beta$-CD. It was observed $\beta-C D$ complexes were better over HP $\beta$-CD. Solubility experiments showed that the concentration of entacapone in water is notably affected by the presence of hydrophilic carriers. The Gibbs free energy values $\left(\Delta G \operatorname{tr}^{\circ}\right)$ associated with the solubility of entacapone in presence of carrier(s) in negative indicate the spontaneous nature of the drug solubilization.

- The IR and DSC studies showed compatibility of drug with the carriers used. The SEM study revealed the existence of the crystalline drug as tiny aggregates of amorphous pieces of irregular sizes. The XRD study indicated the formation of an amorphous complex of drug and $\beta-C D$, dispersed in PEG 4000.

- Photo stability studies indicate that entacapone did not isomerize during the irradiation process.

- Design-Expert software was used for optimization. Response surface plots and contour plots were drawn, and optimum formulations were selected by desirability function. Polynomial mathematical models generated for various response variables using multiple regression analysis were found to be statistically significant ( $p$ $<0.05)$. 


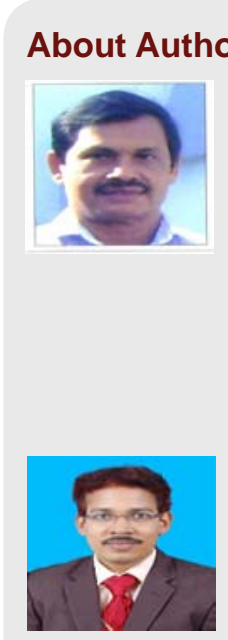

Prof. (Dr.) P. N. Murthy (M. Pharm., Ph. D., D. Sc., F.I.C., C.C), is the Director-cum-Principal, and Head-Dept. of Pharmaceutics, Royal College of Pharmacy and Health Sciences, Berhampur, Odisha. Author of more than 80 peer-reviewed publications, 2 books, and has more than 25 presentations at national and international conferences. An established academician, researcher and administrator with more than 38 years of national and international experience. Served as a consultant, advisor, and visiting professor in countries like Bhutan, Jamaica, Vietnam and Ethiopia etc. He has supervised $13 \mathrm{Ph}$. D., $03 \mathrm{D}$. Sc., and more than $30 \mathrm{M}$. Pharm. candidates. His areas of research interest include formulation development, controlled drug delivery and solubility enhancement of low soluble drugs.

Dr. Anjan Kumar Mahapatra (M. Pharm., Ph. D., F.I.C), is Assoc. Professor, Dept. of Pharmaceutics, Royal College of Pharmacy and Health Sciences, Berhampur, Odisha. Author of 40 peer-reviewed publications, 01 book chapter and has more than 20 presentations at national and international conferences. He has more than 10 years of teaching and research experiences and has guided more than $40 \mathrm{M}$. Pharm. students. His areas of research interest include solubility and dissolution rate enhancement of low soluble drugs. 